\title{
Acute carpal tunnel syndrome from burns of the hand and wrist
}

\author{
Chenicheri Balakrishnan MD, Jason Lee Mussman MD, Anila Balakrishnan BS, Abdullah J Khalil MD
}

C Balakrishnan, JL Mussman, A Balakrishnan, AJ Khalil. Acute carpal tunnel syndrome from burns of the hand and wrist. Can J Plast Surg 2009;17(4):e33-e34.

Acute median nerve compression usually occurs from increased pressure within the carpal tunnel and forearm compartments. Although the hyperesthesia from burns may mimic symptoms of acute compression neuropathy, clinical diagnosis should be made from history, clinical signs and symptoms. Early recognition and decompression of the carpal tunnel either as part of the burn excision or along with escharotomy usually leads to full recovery.

Key Words: Burns of hands and wrist; Median nerve compression neuropathy

\section{Syndrome du tunnel carpien aigu par suite de brûlures à la main et au poignet}

La compression aiguë du nerf médian survient en général par suite d'une pression accrue à l'intérieur des compartiments au niveau du tunnel carpien et de l'avant-bras. Bien que l'hyperesthésie découlant de brûlures puisse imiter les symptômes d'une neuropathie par compression aiguë, le diagnostic clinique doit se fonder sur l'historique, les signes cliniques et les symptômes. Le diagnostic et la décompression rapides du tunnel carpien, soit dans le cadre du débridement d'une brûlure ou lors de l'escharotomie, donnent généralement lieu à un rétablissement complet.
C Compression of the median nerve at the wrist, known as carpal tunnel syndrome, is the most commonly recognized nerve entrapment syndrome. Although various etiologies have been reported for this syndrome, acute compression neuropathy is rare and difficult to diagnose. Early diagnosis of acute carpal tunnel syndrome is usually made from history, and clinical signs and symptoms.

Burns of the hand and wrist are associated with swelling, redness and pain. In third-degree burns, the eschar forms a tight band constricting the circulation distally. This is often relieved by escharotomy. Patients with intermediate-thickness burns involving the hand and wrist may have associated edema that leads to compression neuropathy. The aim of the present study was to determine the clinical features, findings at exploration of carpal tunnel and the outcome following healing of the burn wounds.

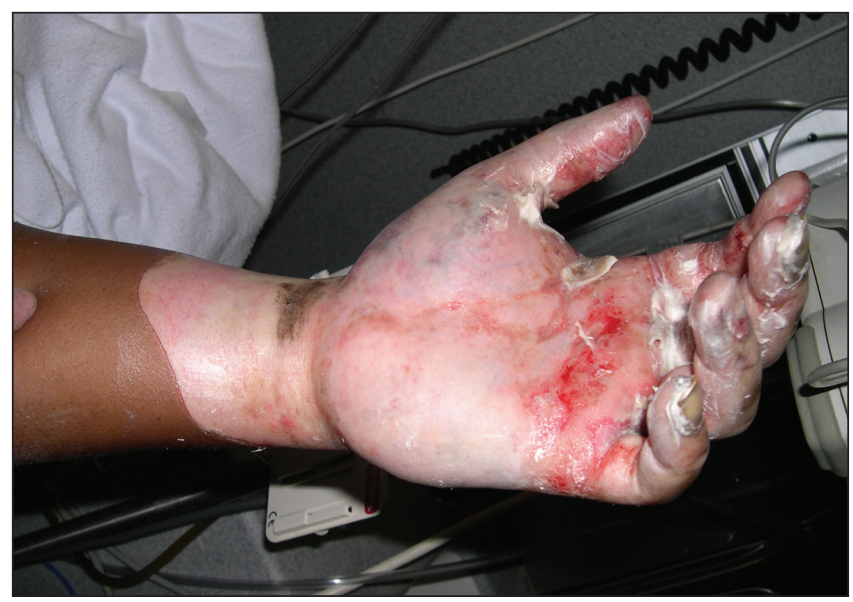

Figure 1) Patient 1 with burns of the hand

\section{METHODS}

During a five-year period, seven patients were treated for acute median nerve neuropathy following flame burns involving the hands. There were five men and two women with a mean age of 27 years. Although the patients had deep dermal burns to the hands on clinical examination (Figures 1 and 2), the symptoms of pain and paresthesia worsened over a period of $24 \mathrm{~h}$ following their injury. There was increasing pain with paresthesia of the median nerve distribution. The two-point discrimination was prolonged on the injured side compared with the other side, and Tinel's test was positive. There was severe pain from passive extension of the fingers and the fingers were kept in a flexed position. A clinical diagnosis of acute median nerve compression was made from clinical signs and symptoms. Although an attempt was made to document the compression neuropathy using an electromyogram and nerve conduction

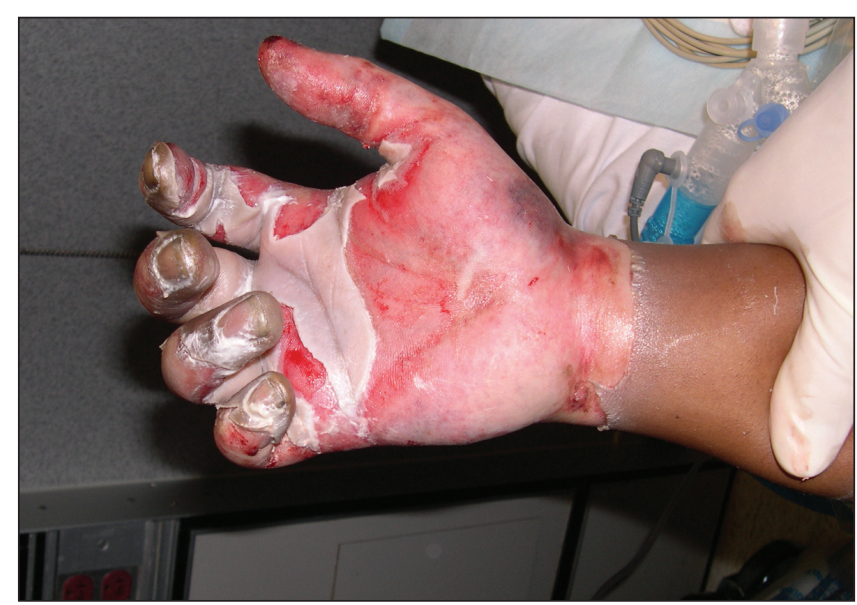

Figure 2) Patient 2 with burns of the hand

Department of Plastic Surgery, Wayne State School of Medicine, Detroit, Michigan, USA

Correspondence: Dr Chenicheri Balakrishnan, Department of Plastic Surgery, John Dingell VA Medical Center, 4646 John R, Detroit, Michigan 48201, USA. Telephone 313-745-3008, fax 313-745-2964, e-mail cbalakri@med.wayne.edu 


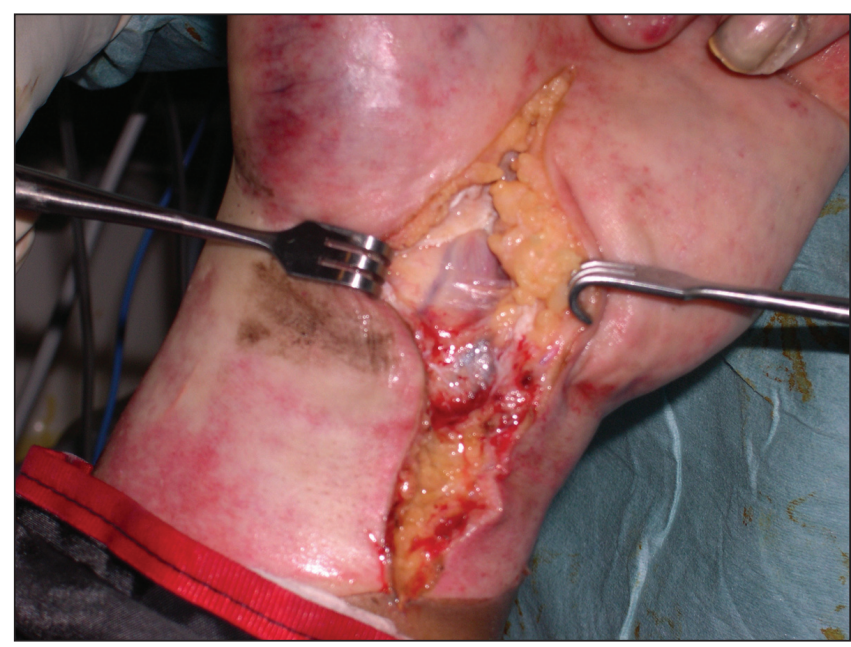

Figure 3) Patient 1 at decompression of carpal tunnel

study, this had to be abandoned due to the burns in the area. Decompression was carried out under general anesthesia in all cases. At decompression there was edema of the contents of the carpal tunnel with fluid inside the carpal tunnel (Figures 3 and 4). The wound was left open and closed after the edema settled. All patients were started on hand therapy at two weeks. Electrodiagnostic studies carried out at six weeks after healing of the wound did not reveal any significant abnormality. There was full recovery in all patients following decompression of the carpal tunnel.

\section{DISCUSSION}

Raised compartment pressure above and beyond a certain level for certain period of time leads to vascular compromise to the structures within the compartment. This ischemia leads to compartment syndrome. The arterioles close before larger vessels within the compartment, which leads to hypoxia of the tissue. Hence, the pulse may be palpable with ischemia of the microcirculation. Thus, an oxygen-nutrient cut off theory has been suggested as the pathophysiology (1). This leads to the signs and symptoms of compartment syndrome.

Various etiologies are associated with compression neuropathy of the median nerve at the wrist. The common etiology for acute carpal tunnel syndrome is fracture around the wrist. Phelan contributed much to the present understanding of the etiology, diagnosis and management of this syndrome (2). Carpal tunnel syndrome is associated with acute pyogenic infection, Hansen's disease, spontaneous hemorrhage, thrombosis of persistent median artery, foreign body, gout, pseudogout and aneurysms of the epineural vessels (3-14). When intracarpal canal interstitial pressure rises above a critical threshold pressure, capillary blood flow is reduced below the level required for median nerve viability. This condition warrants prompt recognition and treatment (11). In acute peripheral nerve compression, preoperative electrodiagnostic examination is usually recommended to confirm the diagnosis. This may not be possible in burn patients due to the presence of open wounds.

Progressive onset of numbness in the median nerve distribution and pain in the fingers on passive extension were the main

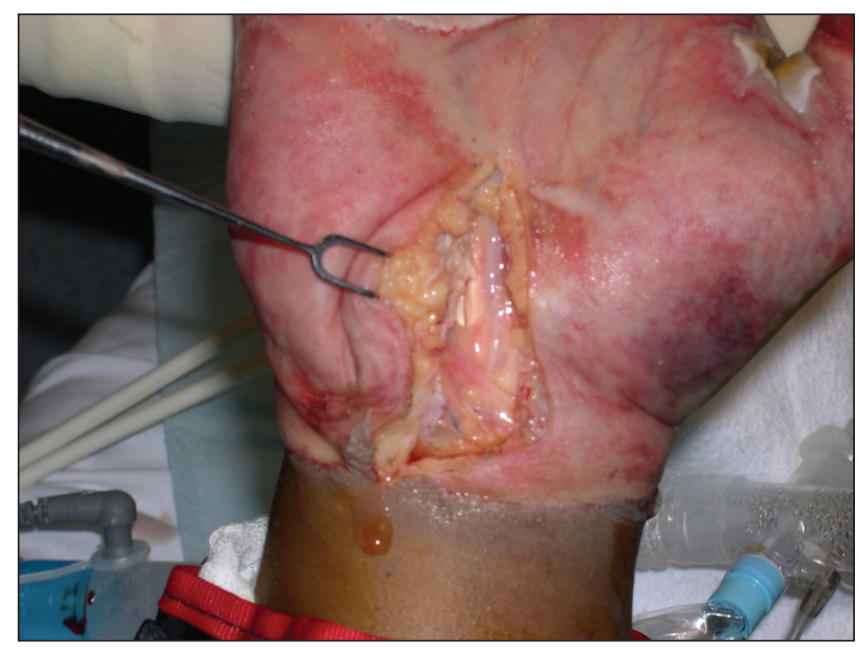

Figure 4) Patient 2 at decompression of carpal tunnel

symptoms in all patients. This was associated with increasing edema of the fingers. Although an attempt was made to obtain a digital Allen's test, this had to be abandoned due to pain. Early exploration and decompression was carried out under tourniquet without exanguination of the extremity. There was edematous fluid inside the carpal tunnel. These patients with the deep burns of the wrist took six weeks to obtain full symptomatic and electrodiagnostic recovery.

\section{REFERENCES}

1. Kumar P. Compartment syndrome: Pathophysiology. Burns 2005;31:120.

2. Phelan GS. The carpal tunnel syndrome: Seventeen years experience in diagnosis and treatment of six hundred fifty-four hands. J Bone Joint Surg 1966;48A:211-8.

3. Lynch AC, Lipscomb PR. The carpal tunnel syndrome and Colle's fracture. JAMA 1963;185:363-6.

4. Mack GR, McPherson SA, Lutz RB. Acute median neuropathy after wrist trauma. The role of emergent carpal tunnel release. Clin Orthop 1994;300:141-6.

5. Gaur SC, Kulahreshtha K, Swarup S. Acute carpal tunnel syndrome in Hansen's disease. J Hand Surg 1994;19B:286-7.

6. Ogilvie C, Kay RM. Fulminating carpal tunnel syndrome due to gout. J Hand Surg 1988;13B:42-3.

7. Balakrishnan C, Jarrahenejad P, Balakrishnan A, Huettner WC. Acute carpal tunnel syndrome as a result of spontaneous bleeding. Can J Plast Surg 2008;16:168-9.

8. Bonatz E, Seabol KE. Acute carpal tunnel syndrome in a patient taking Coumadin: Case report. J Trauma 1993;35:143-4.

9. Balakrishnan C, Smith FM, Puri P. Acute carpal tunnel syndrome from a thrombosed persistent median artery. J Emerg Med 1999;17:437-8.

10. Balakrishnan C, Bradt LM, Sylora RL, Graff N. Acute carpal tunnel syndrome from foreign body in the carpal tunnel. Can J Plast Surg 2002;10:42-3.

11. Szabo RM. Acute carpal tunnel syndrome. Hand Clin 1998;14:419-29.

12. Sterling AP, Eshraghi A, Anderson WJ, Haberman ET. Acute carpal tunnel syndrome secondary to a foreign body within the median nerve. Bull Hosp Joint Dis 1972;33:130-4.

13. Chiu KY, Ng WF, Wong WB, Choi CH, Chow SP. Acute carpal tunnel syndrome caused by pseudogout. J Hand Surg 1992;17A:299302.

14. Fricker R, Fuhr P, Pippert H, Troeger H. Acute median nerve compression at the distal forearm caused by a thrombosed aneurysm of an epineurial vessel: Case report. Neurosurgery 1996;38:194-6. 